\title{
Some aspects of thermal resistance measurement technique for IMPATT and light-emitting diodes
}

\author{
A.E. Belyaev ${ }^{1}$, N.S. Boltovets ${ }^{2}$, R.V. Konakova1, Ya.Ya. Kudryk ${ }^{1}$, \\ V.M. Sorokin ${ }^{1}$, V.N. Sheremet ${ }^{1}$, V.V. Shynkarenko ${ }^{1}$ \\ ${ }^{I} V$. Lashkaryov Institute of Semiconductor Physics, NAS Ukraine \\ 41 Prosp. Nauky, Kyiv 03028, Ukraine; Tel.: (380-44) 525-61-82; e-mail: konakova@isp.kiev.ua \\ ${ }^{2}$ State Enterprise Research Institute “Orion”, 8 a Eugene Pottier St., Kyiv 03057, Ukraine
}

\begin{abstract}
Some aspects of measuring the thermal resistance to a constant heat flow at a $p$ - $n$ junction-package region in IMPATT and light-emitting diodes are considered. We propose a method of studying the thermal resistance of high-power light-emitting diodes. This method makes it possible to increase accuracy of measuring the thermal resistance by determining the temperature at a linear section of the voltage-temperature curve. A possibility to measure the thermal resistance of IMPATT diodes by using the pulse $I-V$ curves is shown. This enables one to simplify calculations and increase accuracy of measuring the thermal resistance.
\end{abstract}

Keywords: $p$ - $n$ junction-package thermal resistance, IMPATT diode, LED.

Manuscript received 27.07.11; revised manuscript received 17.08.11; accepted for publication 14.09.11; published online 30.11.11.

\section{Introduction}

Power increase of optoelectronic and microwave semiconductor devices imposes stringent requirements upon thermal properties of semiconductor microcircuits, discrete devices and contacts to them [1-4]. As the power of light-emitting diodes (LEDs) increases, the peak level of current injection grows. This is accompanied with additional heating that is related to both current passing and nonradiative recombination of charge carriers. Heating the diode active region results in considerable reduction of energy efficiency and activation of degradation processes in semiconductor devices.

The above effects are appreciably related to local nonuniformities in semiconductor structures. Such nonuniformities lead to microplasma breakdown in the impact avalanche transit-time (IMPATT) diodes, pinching in PIN diodes and nonuniform current distribution in LEDs, thus resulting in local increase of diode temperature $T$ and growth of diode thermal resistance $R_{T}$. In this case, the diode electrical parameters change considerably. That is why measurements of $T$ and $R_{T}$ are of interest for prediction of quality and reliability of semiconductor devices - both those operating at forward branch of $I-V$ curve (say,
LEDs) and at reverse branch of $I-V$ curve (IMPATT diodes).

One of the main problems that appear when determining diode thermal resistance is measurement of heating the diode active region. In this case, the noncontact methods of temperature determination (e.g., Raman scattering microspectroscopy [5] and analysis of local photoluminescence [6] and electroluminescence [7] spectra) seem to be more adequate than such contact techniques as scanning thermal microscopy [4] and liquid crystal thermography [8]. However, the simplest techniques are the electrophysical methods for measuring the temperature of diode active region $[9,10]$.

The electrophysical methods involve measurements of temperature-dependent electrophysical parameters, such as the breakdown voltage and forward junction voltage. Different ways of performance measurement are used depending on the generated thermal power and characteristic time of thermal relaxation, as well as device operating mode and package type.

\section{The technique of measurement of LED thermal resistance}

One has from the expression for LED ideal $I-V$ curve (see also [11-13]: 
$\frac{d V}{d T}=\frac{e V-E_{g}}{e T}+\frac{1}{e} \frac{d E_{g}}{d T}-\frac{3 k_{B}}{e}$

Here $V$ is the forward bias voltage, $e$ - electron charge, $k_{B}-$ Boltzmann constant, and $E_{g}-$ semiconductor bandgap energy value.

If one neglects the temperature dependence of charge carrier lifetime in the semiconductor of which the LED is made, then

$\frac{d V}{d T} \approx \frac{k_{B}}{e} \ln \left(\frac{N_{D} N_{A}}{N_{C} N_{V}}\right)-\frac{\alpha T(T+2 \beta)}{e(T+\beta)^{2}}-\frac{3 k_{B}}{e}$.

Here it was taken into account that the temperature dependence of $E_{g}$ is $E_{g}(T)=E_{g}(0)-\frac{\alpha T^{2}}{(\beta-T)}$, where $\alpha$ and $\beta$ are some empirical parameters, $N_{V}\left(N_{C}\right)$ is the effective density of states in the valence (conduction) band, and $N_{D}\left(N_{A}\right)$ - the donor (acceptor) impurity concentration. At $T>270 \mathrm{~K}$, the first and second terms in the right-hand side of Eq. (2) depend on temperature but slightly, therefore $V$ depends on $T$ almost linearly. The slope of the $V(T)$ straight line is said to be as the voltage temperature coefficient (VTC). The gauge dependences $V(T)$ can be obtained by measuring the non-heating $I-V$ curves within the temperature range under consideration, or from direct measurements of $p-n$ junction voltage as a function of the thermostating temperature at a constant non-heating current.

In this case, it should be noted that VTC is meaningful at the exponential portion of the $I-V$ curve only, because the $V(T)$ curve may be nonlinear at other portions of the $I-V$ curve. Therefore, it is desirable to study the $I-V$ curve in the current range concerned before the VTC measurement. Correspondingly, the temperature dependence of forward bias voltage may serve as heat-dependent quantity when measuring the thermal resistance.

The equivalent LED thermal resistance may be measured using a technique in which one performs, at first, gauge measurement of pulsed (non-heating) $I-V$ curves of LED in the 25 to $110^{\circ} \mathrm{C}$ range of package temperature and then diode temperature measurement at maximum permissible current from the gauge $V(T)$ dependence obtained [15]. To exclude heating with passing current when measuring the non-heating $I-V$ curves, one should perform measurements in the pulsed mode. The pulse-repetition interval $\tau_{\mathrm{p}}$ and pulse duration $t_{\mathrm{p}}$ have to obey the inequalities $\tau_{\mathrm{p}} \gg t_{\mathrm{tr}} \gg t_{\mathrm{p}}\left(t_{\mathrm{tr}}\right.$ is the characteristic time of diode thermal relaxation). One should choose a current $I_{F}$ from the set of pulsed $I-V$ curves in such a way that it remained at the exponential portion in the whole temperature range under consideration. The VTC is determined at that fixed current value. Then, at a fixed package temperature, the heating current $I_{h}$ should pass, with the pulse duration $t_{h}$ and pulse-repetition interval $\tau_{h}$ obeying the inequalities $t_{\mathrm{h}}>>t_{\mathrm{tr}}>>\left(\tau_{\mathrm{h}}-t_{\mathrm{h}}\right) . \quad$ A direct current $I_{F}$ passes concurrently with the heating current (that must be equal to the peak LED operation current). At the moment of heating current switch-off, the voltage at the current $I_{F}$ is measured. This voltage value $V_{F}$ enables one to obtain the diode temperature $T_{F}$ from the known VTC, while the $R_{T}$ is calculated from the expression

$$
R_{T}=\frac{T_{F}-T_{K}}{\left(I_{h}+I_{F}\right) V_{h}},
$$

where $T_{K}$ is the diode package temperature.

Determination of the current that corresponds to the exponential portion of the $I-V$ curve in the whole temperature range under investigation enables one to measure more accurately the diode temperature involving VTC. Use of the current $I_{F}$ as a heating one is unreasonable, because this reduces accuracy of measurements. It should be noted that, to obtain thermal resistance of LED from its equivalent thermal resistance, one should perform additional measurements of the portion of radiated light energy.

To illustrate, let us consider the measurement of equivalent thermal resistance of a LUW_W5AM Golden Dragon plus LED. By varying the diode package temperature and using pulses with the repetition interval $\tau_{\mathrm{p}}=200 \mathrm{~ms}$ and duration $t_{\mathrm{p}}=20 \mu \mathrm{s}$ (that do not heat the sample), we obtained the gauge set of pulsed $I-V$ curves in the 20 to $100{ }^{\circ} \mathrm{C}$ temperature range (see Fig. 1). The $V(T)$ curve built at $I_{F}=75 \mathrm{~mA}$ is shown in Fig. 2 .

By passing through the diode heating current pulses $I_{h}=2.2 \mathrm{~A}$ (pulse period $\tau_{\mathrm{h}}=0.2 \mathrm{~s}$ and duration $\left.t_{\mathrm{h}}=0.19998 \mathrm{~s}\right)$ and constant current $I_{F}=75 \mathrm{~mA}$, we measured the voltage (in the intervals between pulses) and determined the diode temperature from the $V(T)$ curve. The LED thermal resistance calculated from the data obtained was

$$
\begin{aligned}
& R_{T}=\frac{T_{F}-T_{K}}{U_{T}\left(\left(I_{T}+I_{F}\right)\right.}=\frac{368 \mathrm{~K}-303 \mathrm{~K}}{4.476 \mathrm{~V} \cdot(2.200 \mathrm{~A}+0.075 \mathrm{~A})}= \\
& =(6.38 \pm 0.03) \mathrm{K} / \mathrm{W} .
\end{aligned}
$$

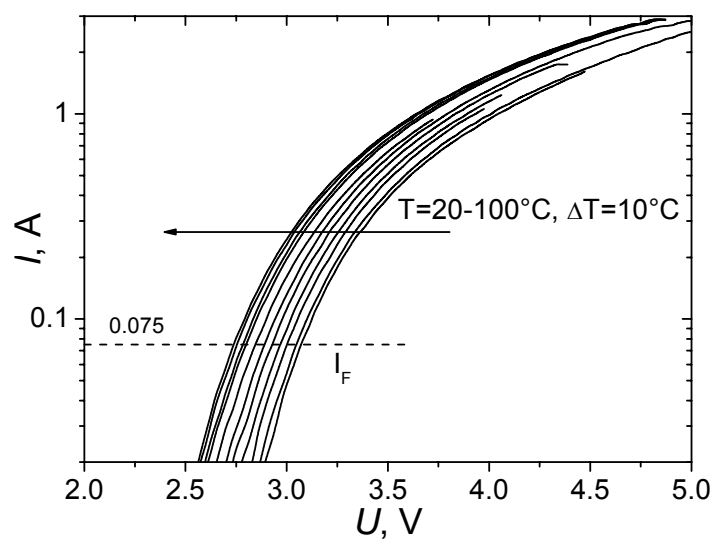

Fig. 1. Pulsed $I-V$ curves of LUW_W5AM Golden Dragon plus LED (pulse period $\tau_{\mathrm{F}}=20 \mu \mathrm{s}$ ) at temperatures $20-100{ }^{\circ} \mathrm{C}$. 


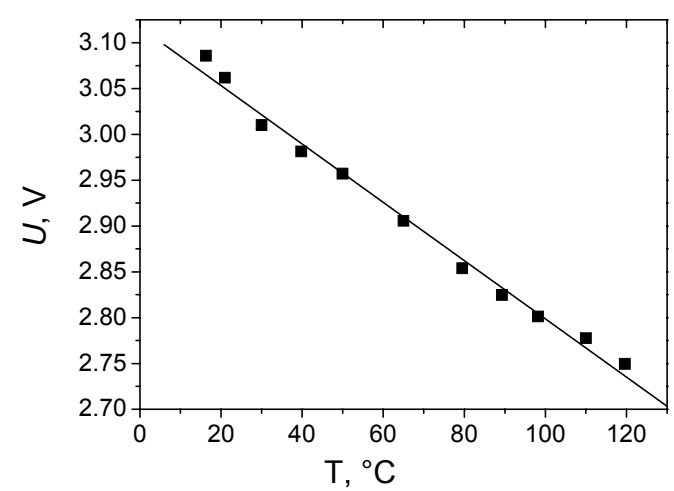

Fig. 2. Temperature dependence of LUW_W5AM Golden Dragon plus LED voltage obtained from the pulsed $I-V$ curves at $I_{F}=75 \mathrm{~mA}$.

The measured values of the thermal resistance corresponded to the rating values (within the experimental errors).

\section{The technique of measuring the IMPATT diode thermal resistance}

When measuring the thermal resistance $R_{T}$ of an IMPATT diode, some additional difficulties appear because of short-term $\left(\sim 10^{-6} \mathrm{~s}\right)$ diode thermal relaxation. Therefore, application of the same method as has been used for LEDs does not enable one to determine $R_{T}$. Measuring the thermal resistance of an IMPATT diode consists in determining the temperature difference between the diode package and $p-n$ junction at dissipation of a certain power of direct current in the diode. According to [14], the measurement of current dependence on the reverse alternating voltage (with the amplitude $V \pm \Delta V$ ) is performed at the package temperature $T_{1}$, on condition that $\Delta I$ does not lead to additional diode heating. As a result, an isothermal $I-V$ curve is obtained. According to our procedure [15], the non-heating $I-V$ curves are determined similarly to the case of LED pulsed $I-V$ curves but with a constant reverse bias. After this, the isothermal $I-V$ curve is measured, too. When measuring the static $I-V$ curve without external heating, the temperature difference $\Delta T$ and power value leading to heating are obtained from its crossing with the isothermal $I-V$ curves.

According to [14], the measurements of $R_{T}$ should be performed with the setup the block diagram of which is presented in Fig. 3. Here, G1 is the constant-current source; G2 - high-frequency current source; G3 reference voltage source; PV1 - reverse voltage amplitude meter; PV2 - constant reverse voltage meter; PT - package temperature meter; E - heater; DUT connecting device with a diode.

In this case, the measurements of $R_{T}$ are performed as follows. The current $I_{0}$ is set with a constant-current source G1. Some voltage $V_{1}$ is set with a reference voltage source G3. The current $I_{0}$ is decreased by $\Delta I$ using the constant-current source G1, and a highfrequency current generator G2 is switched on with an amplitude $\Delta I$. Then, the heater is switched on and the DUT package temperature is measured until the PV1 meter readings coincide with $V_{1}$. The diode reverse voltage is measured with a PV2 meter. The increase of the DUT package temperature, $\Delta T$, is measured with a temperature meter PT. The $R_{T}$ value is determined from Eq. (4):

$R_{T}=\frac{\Delta T}{\Delta I V}-R_{A}$

Here, $V$ is the diode constant reverse current, and $R_{A}$ is the diode package-to-connecting device thermal resistance specified in the technical documentation of the measuring setup (according to GOST 19656.15-84) [14]. A drawback of this method is that the minimum initial current $I_{1}$ is no less than half $I_{0}$ value, thus reducing the accuracy of the method.

Contrary to [14], we measured the IMPATT diode thermal resistance on condition that, instead of a sinusoidal test signal, narrow test pulses of big $\left(Q=10^{4}\right)$ pulse ratio (to reduce power dissipation) were put to the sample [15]. The amplitude of test pulses was increased gradually, thus enabling one to measure pulsed $I-V$ curves of IMPATT diodes. We developed and made a setup to study the diode thermal resistance; its block diagram and appearance are presented in Fig. 4.

Shown in Fig. 5 is the design of a measuring cell for IMPATT diodes. A thermocouple (5) is located inside the IMPATT diode package rather than at the heat sink. This ensures direct measurement of the temperature of IMPATT diode package and makes it possible not to take into account the package-heat sink thermal resistance (contrary to [14]).

The $8 \mathrm{~mm}$-wave IMPATT diodes were made on the basis of $p-n-n^{+}$epitaxial structures; the $n^{+}$-substrate resistivity was $0.002-0.003 \Omega \mathrm{cm}$. The $p^{+}-\mathrm{Si}$ layer was prepared using boron diffusion. The boron concentration in the $p^{+}$-layer was $2 \cdot 10^{20} \mathrm{~cm}^{-3}$; the $p^{+}$-layer thickness was $0.3 \mu \mathrm{m}$. The thicknesses of epitaxial $p$ - and $n$-layers were 0.95 and $1.15 \mu \mathrm{m}$, respectively; the concentrations of acceptor and donor impurities in them were the same $\left(3 \cdot 10^{16} \mathrm{~cm}^{-3}\right)$. The ohmic contacts to the $p^{+}$- and $n^{+}$silicon layers were prepared by depositing $\mathrm{Au}-\mathrm{Pt}-\mathrm{Ti}-\mathrm{Pd}$ layers. The diodes were made with integrated heat sinks.

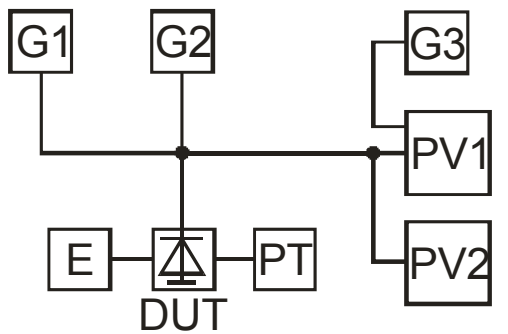

Fig. 3. Block diagram of the setup for measurement of IMPATT diode thermal parameters using temperature dependence of diode reverse voltage: 

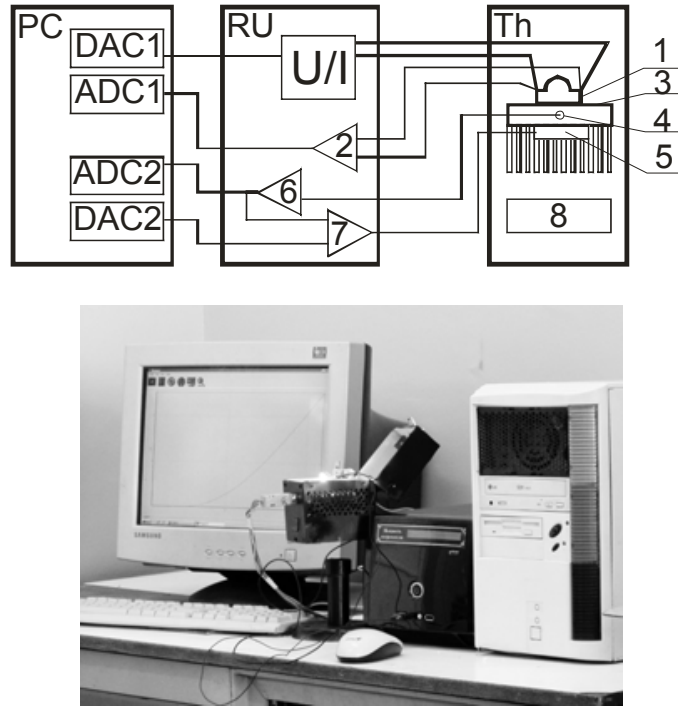

a)

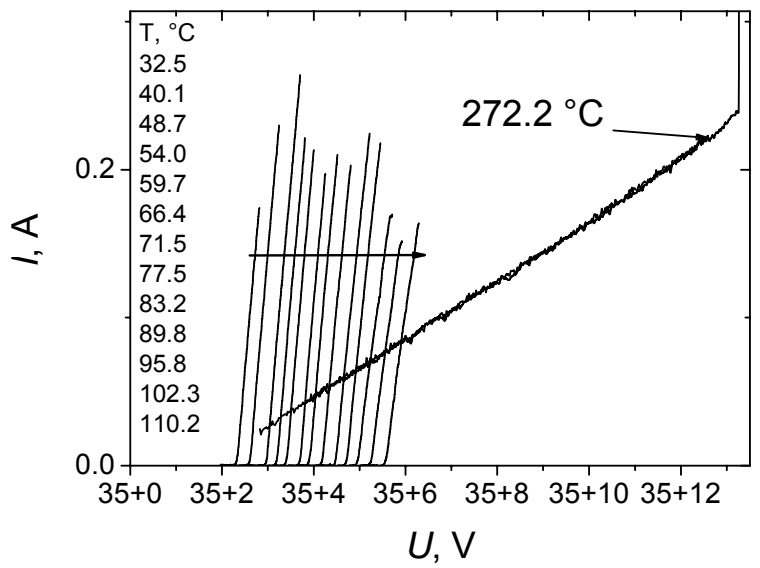

Fig. 6. Pulsed $I-V$ curves of IMPATT diode as a function of package temperature in comparison with the ordinary $I-V$ curve (heavy curve) of the same diode.

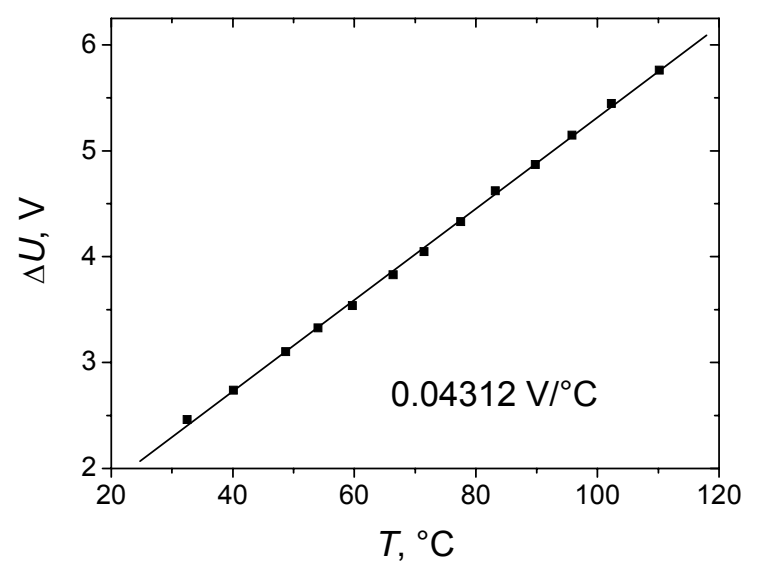

Fig. 7. Temperature dependence of $p-n$ junction voltage at a constant current of $50 \mathrm{~mA}$.

The maximum temperature $\left(272.2^{\circ} \mathrm{C}\right)$ at which no device degradation is observed was obtained from the heating constant of $I-V$ curve (Fig. 6); the slope of the $V(T)$ calibrating curve (Fig. 7) was $0.04312 \mathrm{~V} / \mathrm{K}$. In this case, the package temperature was $121.4^{\circ} \mathrm{C}$, current was $0.22 \mathrm{~A}$, and voltage was $47.6 \mathrm{~V}$. The thermal resistance of the IMPATT diode under investigation was calculated as the ratio of the difference between the $p$ - $n$ junction and package temperatures to the applied power; it was $14.6 \mathrm{~K} / \mathrm{W}$. The obtained $R_{T}$ value is in agreement with the data given in [16].

\section{Conclusions}

The method proposed by us makes it possible to determine thermal resistance of LEDs using the developed setup and taking into account the linear temperature dependence of voltage that is observed only at the exponential portion of the diode $I-V$ curve.
Fig. 5. Structure of the measuring cell for IMPATT diode: 1 IMPATT diode package; 2 - massive copper heat sink; 3 hold-down screw; 4 - pressure contact; 5 - thermocouple cap; 6 - forced cooling radiator. 
Use of pulses of big pulse ratio instead of a sinusoidal test signal (see GOST 19656. 15-84) makes it possible to estimate the temperature of $p$ - $n$ junction overheating in IMPATT diode with lower generation of heat; besides, it fits better for automation of measurements. The direct measurement of temperature of IMPATT diode package enables one not to take into account the package-heat sink thermal resistance. This makes it possible to increase accuracy of measuring the thermal resistance as well as to minimize the effect of random factors (such as the thickness of thermal grease layer and package-heat sink pressing force).

\section{Acknowledgements}

This work is the part of the project "Development and fabrication of a diagnostic complex for testing of microwave diodes based on wide-gap semiconductors (2008-2012)" and project No 31/4.2.3.1/1833 "Development of methods of investigation of contact systems for high-power light-emitting diodes using III group trinitride heterostructures".

\section{References}

1. F.E. Shubert, Light-Emitting Diodes, Cambridge University Press (2006).

2. A.E. Belyaev, N.S. Boltovets, E.F. Venger, R.V. Konakova, Ya.Ya. Kudryk, V.V. Milenin, G.V. Milenin, Physico-Technological Aspects of Degradation of Silicon Microwave Diodes, Akademperiodyka, Kyiv (2011).

3. Yu. Davidenko, High-performance modern lightemitting diodes // Sovremennaya Elektronika No 8, p. 36-43 (2004) (in Russian).

4. D.I. Zaks, Parameters of Thermal Conditions of Semiconductor Microcircuits, Radio i Svyaz', Moscow (1983) (in Russian).

5. W.C. Tang, H.J. Rosen, P. Vettiger, D. Webb, Raman microprobe study of the time development of AlGaAs single quantum well laser facet temperature on route to catastrophic breakdown // Appl. Phys. Lett. 58(6), p. 557-559 (1990).

6. F. Boroumand, M. Voit, D. Lidzey, A. Hammiche, G. Hill, Imaging of heating in a conjugatedpolymer light-emitting diode using a scanning thermal microscope // Appl. Phys. Lett. 84(24), p. 4890-4892 (2004).

7. V.L. Aronov, Ya.A. Fedotov, Testing and Investigation of Semiconductor Devices, Vysshaya Shkola, Moscow (1975) (in Russian).

8. C.C. Lee, J. Park, Temperature measurement of visible light-emitting diodes using nematic liquid crystal thermography with laser illumination // IEEE Photonics Technol. Lett. 16(7), p. 1706-1708 (2004).

9. S.M. He, B. Zhang, N. Li, S.S. Liu, T. Zhang, W. Lu, Junction temperature measurement on lightemitting diodes and its application // Proc. SPIE 7518, p. 75180N (2009).

10. A.E. Belyaev, N.S. Boltovets, E.F. Venger, E.G. Volkov, V.P. Kladko, R.V. Konakova, Ya.Ya. Kudryk, V.V. Milenin, G.V. Milenin, V.A. Pilipenko, R.A. Red'ko, A.V. Sachenko, Physical Methods of Diagnostics in Micro- and Nanoelectronics, ISMA, Kharkov (2011) (in Russian).

11. Y.Xi, J.-Q. Xi, Th. Gessmann, J.M. Shah, J.K. Kim, E.F. Schubert, A.J. Fischer, M.H. Crawford, K.H.A. Bogart, A.A. Allerman, Junction and carrier temperature measurements in deep-ultraviolet light-emitting diodes using three different methods // Appl. Phys. Lett. 86(3), p. 031907-0319007-3 (2005).

12. A. Keppens, W.R. Ryckaert, G. Deconinck, P. Hanselaer, High power light-emitting diode junction temperature determination from currentvoltage characteristics // J. Appl. Phys. 104(9), p. 093104-093104-8 (2008).

13. Q. Shan, Qi Dai, S. Chhajed, Jaehee Cho, E.F. Schubert, Analysis of thermal properties of GaInN light-emitting diodes and laser diodes // $\mathrm{J}$. Appl. Phys. 108(8), p. 084504-084504-8 (2010).

14. State Standard (GOST) 19656. 15-84. Microwave semiconductor diodes. A method of measurement of junction-package thermal resistance and pulse thermal resistance using temperature dependence of forward diode voltage at heating with microwave power pulses (in Russian).

15. O.E. Belyaev, M.S. Boltovets, R.V. Konakova, Ya.Ya. Kudryk, V.M. Sheremet, A method of measurement of thermal resistance of semiconductor diodes // Patent for Useful Model No 65395, Ukraine, 12.12.2011 (in Ukrainian).

16. A.E. Belyaev, V.V. Basanets, N.S. Boltovets, A.V. Zorenko, L.M. Kapitanchuk, V.P. Kladko, R.V. Konakova, N.V. Kolesnik, T.V. Korostinskaya, T.V. Kritskaya, Ya.Ya. Kudryk, A.V. Kuchuk, V.V. Milenin, A.B. Ataubaeva, Effect of $p-n$ junction overheating on degradation of silicon high-power pulsed IMPATT diodes // Semiconductors 45(2), p. 253-259 (2011).

17. Semiconductor Devices. Microwave Diodes. A Handbook, Ed. B.A. Nalivaiko, RASKO, Tomsk (1992) (in Russian). 